\title{
Improved silver staining of nucleolar organiser regions in paraffin wax sections using an inverted incubation technique
}

\author{
G Coghill, A Grant, J M Orrell, J Jankowski, A T Evans
}

\begin{abstract}
A new simple modification to the silver staining of nucleolar organiser regions (AgNORs) was devised which, by performing the incubation with the slide inverted, results in minimal undesirable background staining, a persistent problem. Inverted incubation is facilitated by the use of a commercially available plastic coverplate. This technique has several additional advantages over other published staining protocols. In particular, the method is straightforward, fast, and maintains a high degree of contrast between the background and the AgNORs.
\end{abstract}

The silver staining of nucleolar organiser regions (AgNORs) in paraffin wax sections is a technique which has been adopted only recently by histopathologists. ${ }^{1}$ NORs are loops of ribosomal DNA which encode for ribosomal RNA. Their genes are transcribed by RNA polymerase 1 and are of central importance in directing the formation of both ribosomes and proteins. ${ }^{2}$ Using particular staining conditions the acidic proteins-for example, RNA polymerase $1, \mathrm{~B}_{23}$, and $\mathrm{C}_{23}$ associated with sites of rRNA transcription can be visualised at the optical level, and it is proposed that the number of AgNORs within a cell population reflect cellular and nuclear activity. ${ }^{3}$ In several studies enumeration of AgNORs has now been shown to be of value in discriminating between certain benign and malignant conditions. ${ }^{4-11}$ As a result of encouraging research NOR evaluation will probably soon be transferred to the routine laboratory where it will be of diagnostic value in certain well defined situations.

From discussions with other workers in the field and from our own studies on naevi, melanomas, gastric mucosa and oesophageal mucosa it became clear that even when standard staining protocols were adhered to rigidly the results of the one step silver method could be capricious: in particular, the problem of non-specific background silver staining was troublesome. Using modifications of the technique suggested in the literature, ${ }^{1213}$ some improvement was achieved, but in a considerable number of sections background staining remained unacceptable and precluded accurate AgNOR counting. Further minor adjustments at each stage of the method and attempts at enhancing water purity proved unhelpful. Accordingly, a novel approach to an existing staining protocol was pursued which resulted in the inverted incubation technique.

\section{Methods}

The tissues we studied included gastric and oesophageal mucosa, banal naevi, and cutaneous malignant melanoma. These tissues do not present any particular problem with the AgNOR method. As reported by other workers a small percentage of melanocytic lesions are difficult to evaluate because of dense melanin pigment which obscures nuclear detail. ${ }^{9}$ Such lesions can be disregarded or a standard melanin bleaching procedure ${ }^{14}$ used before silver staining.

Sections were cut at $4 \mu \mathrm{m}$ thickness from formalin fixed, wax embedded blocks, dewaxed in xylene, and transferred to absolute ethanol. Sections were then treated with an acetic acid-ethanol (1:3) mixture for five minutes before being rinsed in absolute ethanol. A colloidal solution of silver was prepared by dissolving $2 \mathrm{~g} / \mathrm{dl}$ gelatine in $1 \mathrm{~g} / \mathrm{dl}$ of aqueous formic acid. This solution was mixed 1:2 volumes with $20 \%$ aqueous silver nitrate. Aliquots (each about $300 \mu \mathrm{l}$ ) of the working solution were then dropped into the shallow depression of a plastic Shandon coverplate (used routinely with the Cadenza/Sequenza immunostainers and available from Shandon Scientific Limited, Runcorn, Cheshire). A glass slide was then placed face down in the solution with accurate positioning being facilitated by plastic guides on the borders of the coverplate. Any excess solution was displaced by the slide leaving a minimum of $100 \mu \mathrm{l}$ in the depression. Using the flexible clip on its undersurface the coverplate was secured to a perspex sheet thus maintaining it in a horizontal position (fig 1). After incubation for 30 minutes at $45^{\circ} \mathrm{C}$ the sections were washed with hot distilled water $\left(45^{\circ} \mathrm{C}\right)$ and then dehydrated, cleared, and mounted permanently in DPX.

\section{Results}

The AgNORs appeared as discrete dark brown to black dots within nuclei which stained pale yellow. Non-specific silver staining was, in most sections, minimal or absent (figs 2,3 , and 4). Overall, this method permitted accurate counting of AgNORs both within nucleoli and lying free within nuclei. 


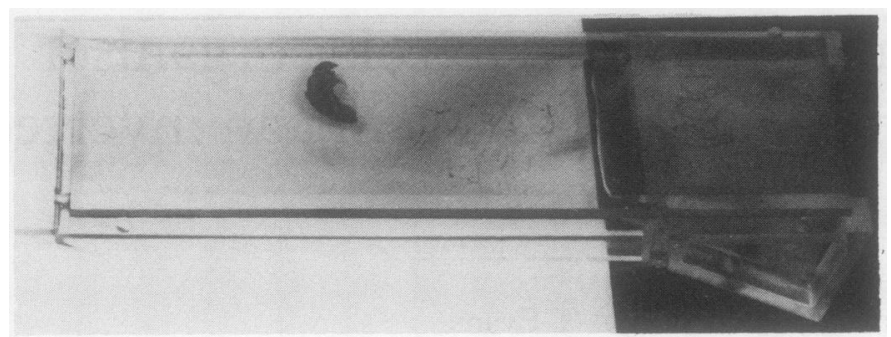

Figure 1 A Shandon coverplate with a slide inverted into colloidal silver soluton.

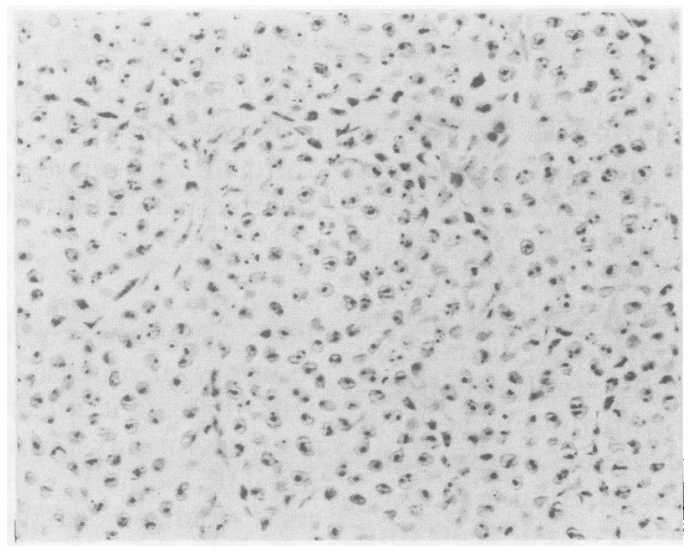

Figure 2 A section of malignant melanoma showing AgNORs stained by the inverted incubation method. At this magnification the absence of unwanted background staining is highlighted.

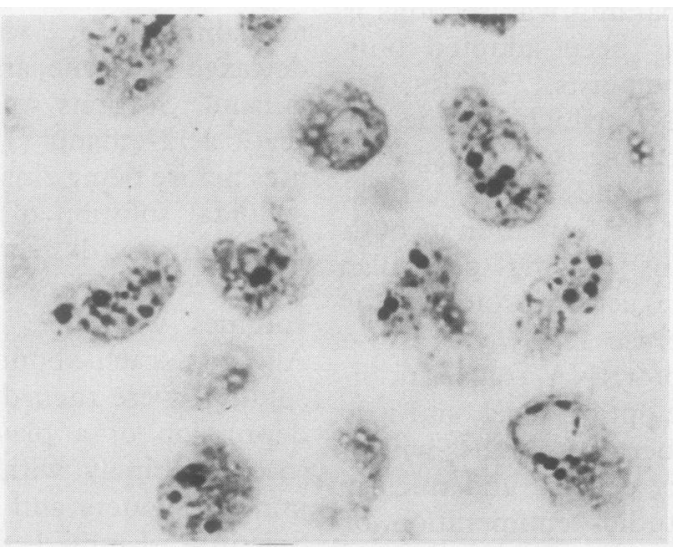

Figure $3 A$ higher power of the same lesion shown in fig 2. Multiple discrete AgNORs are apparent within nuclei. The lack of non-specific staining facilitates rapid and accurate counting.

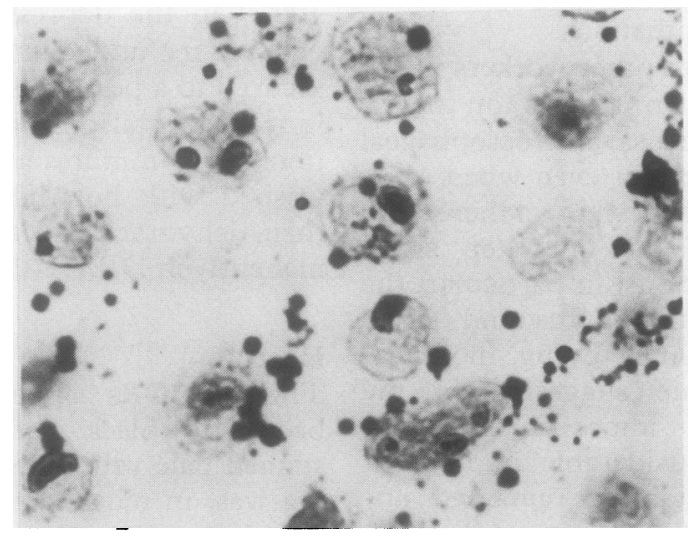

Figure 4 The same lesion as figs 2 and 3 stained by the AgNOR method without inversion. Distracting nonspecific silver deposition is obvious.

\section{Discussion}

This simple modification of the AgNOR method gives excellent reproducible results in routinely fixed and processed material. Distracting background silver granules are few and in many sections they are absent. Incubation of the section face down in the silver solution probably allows reactive NOR associated proteins to precipitate silver, while gravity encourages non-reacting colloidal silver particles to remain in suspension rather than forming unwanted silver aggregates within the tissue.

The technique which we have used is based on that described by Chiu et al, ${ }^{12}$ which is itself adapted from one described by Crocker and Nar. ${ }^{4}$ Like Chiu's group we incubated tissue sections in the AgNOR solution at $45^{\circ} \mathrm{C}$; this gave staining of sufficient intensity using a comparatively short reaction time of 30 minutes. Chiu's group advocate the use of a celloidin film to trap non-specific silver deposits above the tissue section thereby keeping them in a different focal plane. In our experience this modification yields only modest improvements. Diasdvantages include an increase in preparation time and folding and cracking of the celloidin. Moreover, the celloidin film imparts a brown colour to the preparation which decreases the contrast between the background and the AgNORs. Attempts at enhancing AgNOR demonstration by preincubation with a saturated solution of glycine in $99 \%$ ethanol $^{13}$ gave some improvement, but again a significant proportion of sections could not be evaluated because of non-specific staining.

Compared with other modifications our inverted technique has the following advantages. It is straightforward, avoiding further time consuming preincubation treatments. It produces consistent, reproducible results with many sections free of any unwanted silver deposits, and furthermore, a high degree of contrast between the background and the AgNORs is maintained. Little colloidal silver nitrate is used, making the procedure economical. The Shandon coverplate provides an ideal means of keeping slides in an inverted position during incubation, it is compact being little larger than a glass slide, and for this particular procedure it seems to be reusable. Because the modification avoids complicated methodology, large batches of tissue sections can be dealt with simultaneously.

If the AgNOR method is to be used routinely it is essential that the technique be as simple as possible while providing reproducible results in different laboratories. The situation is complicated by reports describing the effects of various fixatives on NOR associated proteins. ${ }^{1516}$ Indeed, local difficulties encountered with the demonstration of AgNORs may relate to fixation or post-fixation procedures and impurities introduced into the tissue at these stages. Most AgNOR research continues to rely on archival material which has usually been preserved in a formaldehyde based fixative. Consequently, attempts to improve the technique must 
optimise results on this type of tissue. In this laboratory tissue is fixed initially in $10 \%$ buffered formalin followed by post-fixation in buffered phenol formaldehyde. ${ }^{17}$ The inverted incubation technique minimises distracting non-specific silver staining in such material.

The melanomas used in part of this study are registered with the Scottish Melanoma Group database. We are grateful to Professor J Swanson Beck and to Dr D Hopwood for advice regarding preparation of the manuscript. We thank Mr R Fawkes for photographic work and also Mrs S Mudie for secretarial assistance. Thanks are also due to Shandon Scientific Limited, Runcorn, Cheshire, for allowing us to describe their coverplate.

1 Anonymous. NORs-A new method for the pathologist [Editorial]. Lancet 1987;i:1413-14.

2 Howell WM, Black DA. Controlled silver staining of nucleolus organizer regions with a protective colloidal developer: a one step method. Experimentia 1980; 36:1104-5.

3 Ploton D, Menager M, Jeannesson P, Himber G, Pigeon F, Adnet JJ. Improvement in the staining and visualization of the argyrophilic proteins of the nucleolar organizer region at the optical level. Histochem J 1986;18:5-14.

4 Crocker J, Nar P. Nucleolar organizer regions in lymphomas. J Pathol 1987;151:111-18.

5 Crocker J, Skilbeck NQ. Nucleolar organiser regionassociated proteins in melanotic lesions of the skin: a quantitative study. J Clin Pathol 1987;40:885-9.
6 Egan M, Raafat F, Crocker J, Smith K. Nucleolar organiser regions in fibrous proliferation of childhood and infantile

7 Egan M, Raafat F,Crocker J, Smith K. Nucleolar organizer regions in small round cell tumours of childhood. J Pathol 1987;153:275-80

8 Egan M, Crocker J. Nucleolar organizer regions in cutaneous tumours. J Pathol 1988;154:247-53.

9 Mackie RM, White SI, Seywright MM, Young H. An assessment of the value of AgNOR staining in the identification of dysplastic and other borderline melanocytic naevi. Br J Dermatol 1989;120:51 1-16.

10 Leong A S-Y, Gilham P. Silver staining of nucleolar organiser regions in malignant melanoma and melanotic

11 Bryan RL, Crocker J, Farr A. Nucleolar organiser regions in kidney tumours and xanthogranulomatous pyelonephritis. J Clin Pathol 1990;43:147-8.

12 Chiu KY, Loke SL, Wang KK. Improved silver technique for showing nucleolar organiser regions in paraffin wax sections. J Clin Pathol 1989;42:992-4.

13 Cromie CJ, Benbow EW, Stoddart RW, McMahon RFT. Preincubation with a glycine solution aids the demonstration of nucleolar organizer region-associated protein. Histochem $J$ 1988;20:722-4.

14 Alexander RA, Hiscott PS, Hart RL. Effect of melanin bleaching on immunoperoxidase, with reference to ocular tissues and lesions. Med Lab Sci 1986;43:121-7.

15 Crocker J, Boldly DAR, Egan MJ. How should we count AgNORs? Proposals for a standardized approach. J Pathol AgNORs? Proposa

16 Griffiths AP, Butler CW, Roberts P, Dixon MF, Quirke P. Silver stained structures (AgNORs) their dependence on tissue fixation and absence of prognostic relevance in rectal adenocarcinoma. $J$ Pathol 1989;159:121-7.

17 Slidders $W$, Hopwood D. Buffered phenol formaldehyde (pH 7.0 and $\mathrm{pH} 5.5$ ): improved fixation in an enclosed tissue processor. Med Lab Sci 1989;46:74-6. 
Infection in the Newborn. Perinatal Practice. Vol 6. Guest eds. J de Louvois, D Harvey. (Pp 163; £39.50.) John Wiley. 1990. ISBN 0-471-92679-5.

This book is the sixth in a series aimed at bridging the gap between obstetrics and neonatology. The volume is based on a workshop on neonatal infection and deals with important areas where there have been advances in our knowledge of the subject. There are separate chapters that review: the inflammatory response to infection; post mortem studies of infection in the newborn; diagnostic tests for bacterial infection; hospital-acquired infections; listeriosis; group B streptococcal infections; human immunodeficiency virus; virological topics; infection in the mother; meningitis and septicaemia. Further chapters cover, respectively, immunoglobulin treatment in neonatal sepsis and antibiotic policies.

The 17 authors have adopted a somewhat different approach to their chapters, some limiting themselves to new aspects, while others comprehensively review the entire subject. Several of the chapters contain previously unpublished data. The chapter on listeriosis amounted to only two and a half pages, and, overall, this chapter was disappointing. The chapter on maternal infections had the largest field to cover and many of the infections were covered excellently despite remarkable brevity; the section on bacteriuria however ignored recent publications which question the cost effectiveness of screening.

Overall, this book should achieve the aims of the series. It is an invaluable source of data and is a welcome addition to my personal library.

RH GEORGE

Pocket Companion to Robbins' Pathologic Basis of Disease. SL Robbins, RS Cotran, V Kumar. (Pp 558; soft cover f13.50.) WB Saunders Company. 1991. ISBN 0-7216-3542-3.

Medical teachers have an understandable tendency to emphasise their own subject and to recommend much larger textbooks than their students can deal with in the time available. Robbins' Pathologic Basis of Disease is a fine large textbook, perhaps the IBM standard for undergraduate pathology texts-the one with which others should be compatible. Most British medical students, with the relatively short time allocated to pathology in the curriculum, tend to use such a volume for reference rather than as a basic textbook.

This "pocket companion" consists of 558 narrow pages (124 general pathology, 362 systemic, 72 index) packed with lists, facts, and references to the parent text. It does fit the pocket and its shape makes for convenient use on public transport. The authors recognise that, as a synopsis, it needs amplification to give understanding and a sense of proportion. For example, in this volume collagenous colitis features in large letters and in almost as much text as diverticular disease. Inevitably such a book contains statements that one considers misleading, wrong, or very economic with the truth. Precis is a difficult art but if used as the authors recommend in conjunction with the parent volume-this could be very helpful text. Other more illicit roles may be as a well structured aidememoire for teachers or for students in the pre-exam cramming that shouldn't be necessary but which usually occurs.

DR DAVIES

In Situ Hybridization. Principles and Practice. Ed JM Polak, JO'D McGee. (Pp 247 ; 25 .) Oxford University Press. 1990 ISBN 0-19-261906-3.

Several generations of cytochemistry have developed descriptive histology into a study of cellular function, and "in situ" hybridisation has added the localisation of cellular and microbial genes and mRNA. This elegant, spiral-bound volume follows the best cytochemical tradition by relating basic molecular biology to bench routines. Molecular and methodological principles are followed by discussion of radioactive and non-isotopic labelling, and the use of oligonucleotide and cRNA probes. The overview on the sensitivity of alternative approaches and on measuring nucleic acid are useful. The value of relating DNA, mRNA, and protein studies to unravel cell phenotypes and control of protein synthesis and storage in neuroendocrine function, factal development, and viral disease is neatly summarised, together with the application of "in situ" hybridisation to cytogenetics.

Discussion of non-isotopic methods for routine histopathological tissue in comparison with other hybridisation methods and the polymerase chain reaction is inevitably inconclusive, given the rapid current developments. A final chapter gives an insight on how the high quality illustrations for this very useful contribution to research methodology were achieved.

D JENKINS

\section{NOTICES}

\section{ACP Locum Bureau}

The Association of Clinical Pathologists runs a locum bureau for consultant pathologists.

Applicants with the MRCPath who would like to do locums and anyone requiring a locum should contact The General Secretary, School of Biological Sciences, Falmer, Brighton, BN1 9QC. Tel and Fax: 0273678435
Clinical epidemiology: principles, methods and applications

September 30-October 4, 1991

Department of Epidemiology/Health Care Research, University of Limburg, Maastricht, The Netherlands.

The following topics will be covered: occurrence measures for disease events, validity and reliability of diagnosis prediction, and measurement of prognosis implementation of study results in daily practice.

Suitable for health care professionals involved in day to day patient management (physicians, nurses, physiotherapists), their teachers and those who are involved in health care research.

Information from $\mathrm{F}$ Hein, Clinica

Epidemiology Course, Faculty of

Health Sciences, University of

Limburg, PO Box 616, 6200 MD

Maastricht, The Netherlands.

Telephone: $31-43887396$.

Telefax: 31-43255643.

\section{First Congress \\ European Society of Histotechnology \\ Amsterdam \\ 22-23 November 1991}

The new European Society of Histotechnology has been formed by representatives of France, Belgium, Holland, Germany, Switzerland, and the United Kingdom. The inaugural congress of the Society will be held at the Academisch Medisch Centrum (AMC) in Amsterdam, and opened by Lee Luna-former President of the NSH (USA). A wide ranging programme, including in situ hybridisation, immunocytochemistry, cytology and morphometry will be presented. Members will have the opportunity to confirm the constitution of the new Society, and to elect officers and representatives to the committee.

Further details of the congress and of membership may be obtained from Mrs M Knowles, ESH, PO Box 121, Macclesfield, Cheshire SK10 3RJ

\section{Erratum}

Our attention has been drawn to an error in the paper "Improved silver staining of nucleolar organiser regions in paraffin wax sections using an inverted incubation technique" by Coghill et al (1990;43:1029-31), in which it was not clearly stated that COVERPLATE, made by Shandon Scientific Limited, Runcorn, Cheshire, is a registered Trade Mark, and not merely a generic descriptive term for the device in question. We wish to make the point understood to avoid future abuse of that Trade Mark. 